\title{
Sexism: Ambivalence toward men
}

\author{
Sezer Ayan ${ }^{1}$
}

\begin{abstract}
Objective. The objective of the study is to test the Ambivalence toward Men Inventory (AMI) that is developed for the purpose of estimating the ambivalence of women towards men on the basis of Ambivalent Sexism.
\end{abstract}

Method. The sample consists of 421 university students. A survey questionnaire was used in the research in order to determine the socio-demographic properties of the participants, and AMI was used in order to measure their social sexism tendencies.

Findings. The general average of AMI is 4,22; and it was seen that men and women have ambivalence above the average towards each other. By gender, there is a significant difference between hostile attitudes towards men $(\mathrm{HM})(\mathbf{t}(\mathbf{4 2 1})=-15,33 \mathrm{p}<0,05)$, and benevolent attitudes towards men $(\mathrm{BM})(\mathrm{t}(421)=-5,18 \mathrm{p}<0,05)$. Sub-factor correlations showed that there is a significant relationship between HM and BM. In contrast with women, encountering a significant relationship between only maternity and compensatory gender differentiation in men showed that women's domestic responsibilities and maturity are determinative in the development of benevolent behaviours in men towards women.

Discussion. The positive relationship observed between HM and BM in AMI shows that women participants resist the male-dominant system on the one hand, while they also have the tendency to justify and support this system.

Keywords: Sexism, ambivalent sexism, hostile and benevolent sexism.

\section{Introduction}

That women as a social group develop ambivalence against men has many reasons (Glick \& Fiske, 1999: 520). While women resent to and resist the fact that men have more control and (structural) power on social, political and economic institutions than them and male-dominant social gender understanding on the one hand, they also admire and have positive emotions involving love towards the men with whom they have heterosexual intimacy. While Glick and Fiske (Glick \& Fiske, 1997: 121) claim that the coexistence of the structural power of men and dyadic power of women (enchaining men as spouses, mothers and emotional partners) in Ambivalent Sexism will create ambivalence consisting of hostile and benevolent attitudes between the genders, they try to measure the ambivalence developed by women against men with Ambivalence Toward Men Inventory (AMI) (Glick \& Fiske, 1999) they developed.

1 Assoc. Prof., Cumhuriyet University, Faculty of Letters, Department of Sociology, Sivas, Turkey, sezerayan@gmail.com 
AMI (Glick \& Fiske, 1999: 520-522) consists of Hostility towards Men (HM) and Benevolence towards Men (BM). Theoretically, these two forms of sexism are associated with three subdimensions (power, gender differentiation and heterosexuality) each having hostile and benevolent aspects.

HM (Glick \& Fiske, 1999: 520) is based on the effort of justifying the power of men by degrading women. Resentment paternalism consists of compensatory gender differentiation and heterosexual bostility sub-components. The resentment paternalism (Glick \& Fiske, 1999: 520) component that is grounded on the social identity theory and prejudice thoughts (Allport, 1954; Tajfel, 1981; 1997) is based on the claim that women who are attributed a negative identity and exposed to prejudiced behaviours by men can develop negative attitudes towards men by resenting to these behaviours. Traditional stereotypes on men generally involve negative content. Glick and Fiske (1999: 520-521) address this situation with the component of "compensatory gender differentiation" in terms of the relationships between the genders, and indicate that women try to differentiate themselves from men with positive properties despite their low status. The last component of HM is Heterosexual hostility. It is claimed that women develop heterosexual hostile attitudes towards men as a result of resisting the sexual aggressiveness of men and the paternal quality of close relationships between genders. According to Glick and Fiske (1999: 521), the sexual aggressiveness of men towards women and sexual violence against women are supported in cultures and sub-cultures in which gender inequality is approved. For, sexual aggressiveness of men is regarded as a popular means of maintaining inequality by controlling women's sexuality in such cultures. Heterosexual hostility is thus described as the resistance of women, who are aware of the threat in question and affected by it, towards men.

On the other hand, according to Glick and Fiske (1999: 521), the attitudes of women towards men do not only include hostility. Just like many men are enchained to women, most women are also enchained to men. For, traditionally women get the opportunity to have social status and economical guarantee through men. Furthermore, being enchained to the opposite sex also contains sexual reproduction and heterosexual romantic relationships. It is possible that these factors motivate woman towards developing subjectively positive attitudes towards men. The second sub-factor of AMI, Benevolence towards Men (BM) depends on the ideas that idealize women as pure creatures that must be protected and verify the enchainment of men to women. BM involves the sub-components maternalism, complementary gender differentiation and heterosexual intimacy. The first component of BM, maternity is based on the idea that women assume that men are weak and develop attitudes and behaviours that will justify their own benevolence and protective qualities towards them. Benevolence towards men may result from the admiration for the high status of men. Complementary gender differentiation is based on the idea that assumes that women are less ambitious, intelligent and skilful than men, thus they can develop respect for the power and skills of men, while women complete men with other properties (such as, being skilful in household chores, being self-sacrificing, etc.) The last benevolence towards men is the heterosexual intimacy that is based on the idea that the love bond between women and men results from heterosexual attractiveness.

This study aims to measure sexism in terms of both men and women separately, in a way that it includes negative and positive attitudes in traditional terms by using "Ambivalence toward Men Inventory". The importance of the study arises from the fact that previous studies on sexism were mainly woman-centred, they focused on measuring the attitudes on the roles attributed to women socially, while the attitudes towards men in the dominant position have not been sufficiently studied so far. 


\section{Methodology}

The universe of the study consists of the students (17.976) maintaining their normal education in 13 faculties and 3 vocational higher schools of Cumhuriyet University. The number of the sample was calculated as 317 through proportional stratified sampling, however the participation of 422 students in total from 10 faculties and 3 vocational higher schools was ensured considering the validity and reliability of the research. Questionnaire form and social sexism scales were used for obtaining the data. The practice was carried out between 02-01-2012 and 04-30-2012 with the permission of the Rectorship of Cumhuriyet University.

The questionnaire form consists of 10 questions arranged in order to determine the sociodemographical properties of the students.

Ambivalence toward Men Inventory. AMI that is developed by Glick and Fiske (1999) consists of 19 items. 10 items in the inventory (Table 2) measure hostility towards men (HM), while 9 items measure benevolence towards men (BM). The participants stated the extent that they agree with each of the items in 6-item likert scale. In this scale, 1 means "I totally disagree", while 6 means "I totally agree". The expression "neither agree nor disagree" was not included in the inventory. High scores obtained from the inventory show that hostility and benevolence towards men are high.

As a result of the confirmatory factor analysis performed by Glick and Fiske (1999: 524), they indicated that the factor structure that best represents AMI is the two factors consisting of $\mathrm{HM}$ and BM and three sub-factors they include (For hostile sexism; resentment paternalism, compensatory gender differentiation and heterosexual hostility. For benevolent sexism; maternalism, complementary gender differentiation and heterosexual intimacy). The scale was first translated into Turkish by Sakallı Uğurlu (2008) for the study of Glick et al. (2004) and applied in Turkey, as well. In the internal consistency reliability analysis performed for this study, Cronbach's $\alpha$ coefficient calculated for the scale was found as 0.78 (N-422, item number-19); Cronbach's $\alpha$ coefficient for HM as 0.73 and Cronbach's $\alpha$ coefficient for BM as 0.74 . That none of the variables has a negative relationship with the total correlation shows that the internal consistency reliability of the scale is good. For, the coefficient 0.70 was deemed sufficient for reliability (McIntire \& Miller, 2000, aktaran Sakallı Uğurlu, 2008: 8). On the other hand, Cronbach's $\alpha$ coefficients in this study are highly consistent with the studies of Glick and Fiske (1999: 2004) and Sakallı Uğurlu (2008: 8).

\section{Statistical analysis}

Data obtained from the research were presented in four tables. Table 1 consists of general findings. Table 2 includes the general average of the responses given to the expressions in AMI. In Table 3, whether the scores obtained by the students from AMI vary by the gender of the students was analysed using t-test. Table 4 was organized for the purpose of determining which attitudes of female and male participants are more determining in the development of ambivalence towards men. The analyses were performed at the reliability level of 95\%, and SPSS 16.0 package program was used for the analyses. 
Ayan, S. (2016). Sexism: Ambivalence toward men. International Journal of Human Sciences, 13(1), 1452-1459. doi:10.14687/ijhs.v13i1.3636

\section{Results}

Table 1. General findings

\begin{tabular}{l|l|l}
\hline Gender & Number & $\%$ \\
\hline Female & 252 & 59,7 \\
\hline Male & 169 & 40,0 \\
\hline Department & & \\
\hline Medicine & 31 & 7,3 \\
\hline Dentistry & 10 & 2,4 \\
\hline Literature & 78 & 18,5 \\
\hline Science & 38 & 9,0 \\
\hline Economics & 57 & 13,5 \\
\hline Communication & 5 & 1,2 \\
\hline Engineering & 31 & 7,3 \\
\hline Health sciences & 60 & 14,2 \\
\hline Fine arts & 10 & 2,4 \\
\hline Religion & 5 & 1,2 \\
\hline BESYO & 10 & 2,4 \\
\hline CMYO & 43 & 10,2 \\
\hline SMYO & 43 & 10,2 \\
\hline CYI & 1 & 0,2 \\
\hline Total & 421 & 99.8 \\
\hline BESYO: Physi & E &
\end{tabular}

BESYO: Physical Education and Sports Higher School (Beden Ë̆itimi ve Spor Yüksekokulu); CMYO: Cumhuriyet Vocational Higher School (Cumburiyet Meslek Yüksekokulu); SMYO: Sivas Vocational Higher School (Sivas Meslek Yükesekokulu).

Table 2. Responses to the Expressions in AMI Scale

\begin{tabular}{|c|c|c|c|c|c|c|c|}
\hline & & \multicolumn{2}{|c|}{ General } & \multicolumn{2}{|c|}{ Female } & \multicolumn{2}{|l|}{ Male } \\
\hline & & $\mathrm{O}$ & SD & $\mathrm{O}$ & SD & $\mathrm{O}$ & $\mathrm{SD}$ \\
\hline & Hostile Sexism & 4,26 & 1,51 & 5,14 & 1,28 & 3,58 & 1,70 \\
\hline & Resentment paternalism & 4,75 & 1,33 & 5,10 & 1,12 & 4,23 & 1,42 \\
\hline 8 & $\begin{array}{l}\text { Men always strive for having more control in the } \\
\text { society than men }\end{array}$ & 4,75 & 1,69 & 5,05 & 1,05 & 4,31 & 1,48 \\
\hline 10 & $\begin{array}{l}\text { Even men who claim that they are sensitive against women } \\
\text { rights want a traditional relationship in which household } \\
\text { chores and child care are undertaken by the women }\end{array}$ & 4,92 & 1,19 & 5,11 & 1,17 & 4,62 & 1,16 \\
\hline \multirow[t]{2}{*}{14} & $\begin{array}{l}\text { Most men supposedly defend equity for women but cannot } \\
\text { stand seeing a woman equal to themselves }\end{array}$ & 4,59 & 1,53 & 5,15 & 1,16 & 3,76 & 1,64 \\
\hline & Compensatory Gender Differentiation & 4,07 & 1,64 & 4,67 & 1,34 & 4,67 & 1,34 \\
\hline 5 & $\begin{array}{l}\text { Men would lose their way in the world if it was not } \\
\text { for women who would show them the way }\end{array}$ & 3,47 & 1,76 & 4,04 & 1,63 & 2,62 & 1,59 \\
\hline 7 & Men act like babies when they get sick & 4,53 & 1,57 & 5,21 & 1,08 & 3,52 & 1,65 \\
\hline \multirow[t]{2}{*}{16} & In their essence, most men are like babies indeed & 4,23 & 1,61 & 4,77 & 1,33 & 3,42 & 1,66 \\
\hline & Heterosexual hostility & 4,05 & 1,53 & 4,48 & 1,35 & 3,4 & 1,57 \\
\hline 2 & $\begin{array}{l}\text { A man typically has no ethical value in terms of doing } \\
\text { anything to get a woman he finds sexually } \\
\text { attractive to bed }\end{array}$ & 4,04 & 1,79 & 4,57 & 1,57 & 3,26 & 1,82 \\
\hline 3 & $\begin{array}{l}\text { While men seem to be helping women, they mostly } \\
\text { try to prove that they are better than women }\end{array}$ & 3,87 & 1,56 & 4,33 & 1,38 & 3,18 & 1,55 \\
\hline 13 & Men generally try to be dominant while talking to women & 4,54 & 1,26 & 4,86 & 1,08 & 4,05 & 1,36 \\
\hline \multirow[t]{3}{*}{18} & $\begin{array}{l}\text { Most men sexually harass women, even if it is implicitly, at the } \\
\text { moment they achieve a position they have power on women }\end{array}$ & 3,75 & 1,54 & 4,17 & 1,37 & 3,11 & 1,56 \\
\hline & Benevolent sexism & 4,18 & 1,69 & 4,0 & 1,53 & 4,45 & 1,48 \\
\hline & Maternalism & 4,00 & 1,64 & 3,91 & 1,61 & 4,13 & 1,62 \\
\hline 1 & $\begin{array}{l}\text { Even if both parties of the couple work, women } \\
\text { must undertake more responsibility in terms of }\end{array}$ & 4,12 & 1,69 & 3,83 & 1,69 & 4,56 & 1,59 \\
\hline
\end{tabular}


Ayan, S. (2016). Sexism: Ambivalence toward men. International Journal of Human Sciences, 13(1), 1452-1459. doi:10.14687/ijhs.v13i1.3636

looking after her man at home

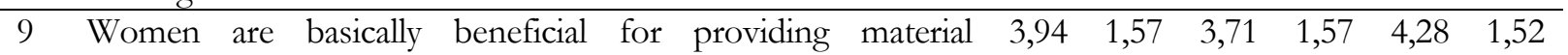
guarantee to men

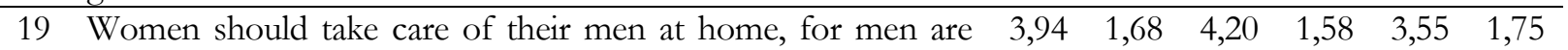
not able to look after themselves if they have to

\begin{tabular}{lllllll} 
Complementary gender differentiation & 4,68 & 1,29 & 4,51 & 1,30 & 4,93 & 1,22 \\
\hline
\end{tabular}

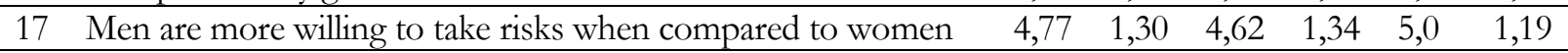

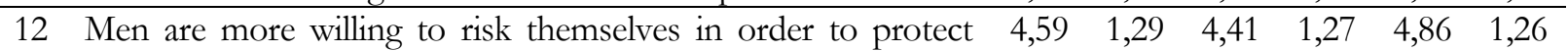
others

\begin{tabular}{|c|c|c|c|c|c|c|c|}
\hline & Heterosexual intimacy & 4,07 & 1,92 & 3,82 & 1,47 & 4,46 & 1,52 \\
\hline 4 & $\begin{array}{l}\text { Each woman needs a man who shows great respect } \\
\text { to her }\end{array}$ & 4,45 & 1,51 & 4,29 & 1,56 & 4,69 & 1,41 \\
\hline 6 & $\begin{array}{l}\text { If a woman does not have a long-term enchained } \\
\text { relationship with a man, she may not be deemed to } \\
\text { complete herself in this life in the real sense }\end{array}$ & 3,66 & 1,61 & 3,50 & 1,63 & 3,90 & 1,57 \\
\hline 11 & Each woman must have a man that she admires & 4,29 & 1,65 & 4,17 & 1,68 & 4,47 & 1,60 \\
\hline \multirow[t]{2}{*}{15} & Women are incomplete without men & 3,91 & 2,93 & 3,33 & 3,47 & 4,78 & 1,50 \\
\hline & GENERAL & 4,22 & 1,59 & 4,38 & 1,51 & 3,99 & 1,51 \\
\hline
\end{tabular}

When the general average of the scores taken from AMI are examined in Table 2, it was determined that the ambivalence of the participants towards each other is above the average (with $A=4,22)$; and women $(A=4,38)$ have more ambivalence than men $(A=3,99)$.

Table 3. Difference of the scores taken from hostile sexism and benevolent sexism in AMI

\begin{tabular}{llllll}
\hline $\begin{array}{l}\text { Total Data } \\
(421)\end{array}$ & Sex & O & SD & Z/F & P \\
\hline HM & Female & 5,14 & 1,28 & 15.33 & .00 \\
& Male & 3,58 & 1,70 & & \\
\hline BM & Female & 4,01 & 1,53 & $-5,18$ & .00 \\
& Male & 4,45 & 1,48 & & \\
\hline $\mathrm{P}<0,05$ & $\mathrm{p}<0,01$ & & & &
\end{tabular}

It was found that there is a significant difference between the participants by gender in terms of hostility $(\mathrm{t}(421)=-15,33 \mathrm{p}<0,05)$ and benevolence $(\mathrm{t}(421)=-5,18 \mathrm{p}<0,05)$. Upon examining the general average of the scores obtained from AMI, it is seen that female participants $(A=5,14$, $S=1,28)$ had higher scores in HM than male participants $(A=3,58, S=1,70)$, while male participants $(A=4,45, S=1,53)$ had higher scores in $B M$ than female participants $(A=4,01, S=1,53)$.

Table 4. Sub-factor correlations of AMI

\begin{tabular}{|c|c|c|c|c|c|c|c|c|c|c|}
\hline $\begin{array}{l}\text { FOR THE WHOLE } \\
\text { DATA }\end{array}$ & $\mathrm{M}$ & $\mathrm{SD}$ & AMI & $\mathrm{HM}$ & $\mathrm{RP}$ & CSGD & $\mathrm{HH}$ & $\mathrm{BM}$ & $\mathrm{M}$ & CMGD \\
\hline AMI & 4,23 & 0,71 & & & & & & & & \\
\hline HM & 4,27 & 0,93 & $0,79^{* *}$ & & & & & & & \\
\hline R P & 4,75 & 0,99 & $0,67^{* *}$ & $0,79^{* *}$ & & & & & & \\
\hline CSGD & 4,07 & 1,28 & $0,64^{* *}$ & $0,84^{* *}$ & $0,56^{* *}$ & & & & & \\
\hline $\mathrm{HH}$ & 4,05 & 1,06 & $0,67^{* *}$ & $0,86^{* *}$ & $0,53^{* *}$ & $0,55^{* *}$ & & & & \\
\hline BM & 4,18 & 1,69 & $0,73^{* *}$ & $0,16^{* *}$ & $0,19^{* *}$ & $0,10^{*}$ & $0,12^{*}$ & & & \\
\hline $\mathrm{M}$ & 4,00 & 1,64 & $0,56^{* *}$ & $0,18^{*}$ & $0,18^{* *}$ & $0,14^{* *}$ & $0,14^{* *}$ & 0,70 & & \\
\hline CMGD & 4,68 & 1,29 & $0,42^{* *}$ & $0,10^{*}$ & $0,14^{* *}$ & $-0,00$ & $0,12^{*}$ & $0,57^{* *}$ & $0,28^{* *}$ & \\
\hline $\mathrm{HI}$ & 4,07 & 1,92 & $0,60^{* *}$ & 0,09 & $0,13^{* *}$ & 0,06 & 0,05 & $0,87^{* *}$ & $0,36^{* *}$ & $0,30^{* *}$ \\
\hline \multicolumn{11}{|l|}{ WOMEN } \\
\hline AMI & 4,38 & 0,72 & & & & & & & & \\
\hline $\mathrm{HM}$ & 4,73 & 0,73 & $0,81^{* *}$ & & & & & & & \\
\hline R P & 5,10 & 0,85 & $0,63^{* *}$ & $0,78^{* *}$ & & & & & & \\
\hline
\end{tabular}


Ayan, S. (2016). Sexism: Ambivalence toward men. International Journal of Human Sciences, 13(1), 1452-1459. doi:10.14687/ijhs.v13i1.3636

\begin{tabular}{|c|c|c|c|c|c|c|c|c|c|c|}
\hline CSGD & 4,67 & 1,02 & $0,66^{* *}$ & $0,78^{* *}$ & $0,48^{* *}$ & & & & & \\
\hline $\mathrm{HH}$ & 4,48 & 0,89 & $0,65^{* *}$ & $0,82^{* *}$ & $0,48^{* *}$ & $0,42^{* *}$ & & & & \\
\hline BM & 4,01 & 0,97 & $0,87^{* *}$ & $0,42^{* *}$ & $0,33^{* *}$ & $0,37^{* *}$ & $0,32^{* *}$ & & & \\
\hline $\mathrm{M}$ & 3,91 & 1,16 & $0,63^{* *}$ & $0,31^{* *}$ & $0,21^{* *}$ & $0,27^{* *}$ & $0,26^{* *}$ & $0,72^{* *}$ & & \\
\hline CMGD & 4,51 & 1,13 & $0,50^{* *}$ & $0,31^{* *}$ & $0,27^{* *}$ & $0,19^{* *}$ & $0,27^{* *}$ & $0,51^{* *}$ & $0,29^{* *}$ & \\
\hline $\mathrm{HI}$ & 3,82 & 1,46 & $0,73^{* *}$ & $0,33^{* *}$ & 0,26 & $0,32^{* *}$ & $0,21^{* *}$ & $0,87^{* *}$ & $0,37^{* *}$ & $0,21^{* *}$ \\
\hline \multicolumn{11}{|l|}{ MEN } \\
\hline AMI & 4,00 & 0,63 & & & & & & & & \\
\hline $\mathrm{HM}$ & 3,58 & 0,76 & $0,83^{* *}$ & & & & & & & \\
\hline $\mathrm{RP}$ & 4,23 & 0,96 & $0,66^{* *}$ & $0,70^{* *}$ & & & & & & \\
\hline CSGD & 3,18 & 1,12 & $0,57^{* *}$ & $0,75^{* *}$ & $0,36^{* *}$ & & & & & \\
\hline $\mathrm{HH}$ & 3,40 & 0,98 & $0,64^{* *}$ & $0,78^{* *}$ & $0,32^{* *}$ & $0,34^{* *}$ & & & & \\
\hline BM & 4,45 & 1,48 & $0,79^{* *}$ & $0,33^{* *}$ & $0,36^{* *}$ & $0,16^{*}$ & $0,23^{* *}$ & & & \\
\hline $\mathrm{M}$ & 4,13 & 1,62 & $0,57^{* *}$ & $0,28^{* *}$ & $0,30^{* *}$ & $0,18^{*}$ & $0,28^{* *}$ & $0,68^{* *}$ & & \\
\hline CMGD & 4,93 & 1,05 & $0,50^{* *}$ & $0,19^{* *}$ & $0,22^{* *}$ & 0,00 & $0,21^{* *}$ & $0,64^{* *}$ & $0,22^{* *}$ & \\
\hline $\mathrm{HI}$ & 4,46 & 1,05 & $0,66^{* *}$ & $0,25^{* *}$ & $0,27^{* *}$ & 0,13 & $0,25^{* *}$ & $0,85^{* *}$ & $0,29^{* *}$ & $0,41^{* *}$ \\
\hline
\end{tabular}

$\mathrm{AMI}=$ Ambivalence toward men inventory, $\mathrm{HM}=$ Hostility toward men, $\mathrm{RP}=$ Resentment paternalism, $\mathrm{CSGD}=$ Compensatory gender differentiation, $\mathrm{HH}=$ Heterosexual hostility, $\mathrm{BM}=$ Benevolence toward men, $\mathrm{M}=\mathrm{Maternalism}$, $\mathrm{CMGD}=$ Complementary gender differentiation, $\mathrm{HI}=$ Heterosexual intimacy

That sub-factors are highly correlated with scale scores in AMI shows that there is a strong and positive relationship between them. Between $\mathrm{HM}$ and $\mathrm{BM}$, there is a statistically positive relationship both the total data $(\mathrm{r}=0,16, \mathrm{~N}=421, \mathrm{p}<.01)$ and between female $(\mathrm{r}=0,42, \mathrm{~N}=252, \mathrm{p}$ $<.01)$ and male participants $(\mathrm{r}=0,33, \mathrm{~N}=169, \mathrm{p}<.01)$. While a significant relationship is observed between all sub-factors of HM and BM among female participants, a positive relationship was encountered only between the compensatory differentiation and maternalism $(r=0,18 \mathrm{p}>.01)$ subfactors among male participants.

\section{Discussion}

$59 \%$ of the participants of the research are female while $40 \%$ are male (Table 1). The general average (Table 2) of the scores taken from AMI shows that men and women have benevolence towards each other but women have more benevolence than men. Upon examining the sub-factor averages of AMI in terms of female and male participants (Table 2), that women who were determined to be more hostile towards men had the highest scores from the resentment paternalism sub-factor shows that hostility of women towards men results from their resentment to the power of the men and the abuse of this power. On the other hand, that men who were determined to be more benevolent towards women had the highest scores from the sub-factors of compensatory gender differentiation and heterosexual intimacy shows that these are the men who support traditional gender roles and stereotypes, with a clearer expression, who perceive women weaker in social and emotional sense and think that they should be helped. The variance analysis performed (Table 3) shows that there is a significant difference between the participants in terms of hostility and benevolence by gender. While female participants agree with the hostility towards men that consists of resentment paternalism, compensatory gender differentiation more, male participants agree with benevolence towards men that consists of maternalism, complementary gender differentiation and heterosexual intimacy more. That women agree more with hostility towards men who negatively estimate traditional attitudes towards men can be indicator that they developed hostility towards men by resenting to the male dominancy in traditional sexist order and the high status of men in the society. On the other hand, the reason for men's agreeing with benevolence towards men that is in a positive tone and defend that men must be maternally 
protected by women at home may be that they want to justify the existing male dominance and maintaining men's traditional gender roles (Sakallı Uğurlu, 2008: 9).

The data obtained from the correlation analysis performed in order to determine which attitudes of female and male participants are more determining in the development of ambivalence towards men (Table 4) are important in that they show that women are associated more with household responsibilities by men and their maternal attitudes are more determining in the development of their benevolence towards women than other attitudes. In other words, we can say that the efforts of women to differentiate themselves from men and think that they are superior to men (maternalist attitude) are approved by men when it comes to household chores. On the other hand, although female participants agree with the HM sub-factor that negatively estimate traditional attitudes towards men more (Table 3), that a significant association was formed between HM and $\mathrm{BM}$ and all their sub-factors only in female participants shows that while women resent to men and exhibit negative attitudes towards them, they do not say no to being protected by them and can prefer the benevolent part of sexism, too.

\section{Conclusion}

This study is one of the first studies in which Ambivalence Toward Men Inventory (except for the studies on its adaptation into Turkish), which was developed based on Ambivalent Sexism theory and brings about a new point-of-view about sexism by adding the attitudes towards men, are tested on a particular sample group. The difference of the study from other studies is that the correlations between the sub-factor components of AMI were examined, and thus it was tried to determine which attitudes at hostile and benevolent level were determining in the development of ambivalence between the sexes. The data obtained from the correlation analysis show that women are associated more with household responsibilities by men and their maternal attitudes are more determining in the development of their benevolence towards women than other attitudes. In other words, the efforts of women to differentiate themselves from men and think that they are superior to men (maternalist attitude) are approved by men when it comes to household chores. On the other hand, although female participants agree with the HM sub-factor, that a significant association was formed between HM and BM and all their sub-factors only in female participants shows that while women resent to men and exhibit negative attitudes towards them, they do not say no to being protected by them and can prefer the benevolent part of sexism, too. When these results are compared with the results of previous researches (Glick \& Fiske, 1999; 2004; Sakallı Uğurlu, 2008), it can be said that there has not been a big change among women in terms of sexism although they resist the present order and women tend to justify the sexism and male-dominant system presented in a positive tone (Sakallı Uğurlu, 2008: 10).

Although Glick and Fiske (1999: 522) indicate that ambivalence towards men caused by emotions and thoughts arising from hostile and benevolent dimensions is possible in samples that view men more traditionally, that studies carried out in this area so far have been carried out on sample groups consisting of university students and the results obtained are consistent with the arguments specified in the theoretical background are important in that students maintaining their education in Turkish universities have traditional attitudes in terms of social sexism. The data obtained from study show that

On the other hand, the results of AMI on a sample group that does not consist of students require a new study. 


\section{References}

Allport, G. W. (1954). The Nature of Prejudice. Reading, MA: Addison-Wesley.

Glick, P., \& Fiske, S. T. (1997). Hostile and Benevolent Sexism: Measuring Ambivalent Sexist Attitudes Toward Women. Psychology of Women Quarterly, 21(1), 119-135. doi: 10.1111/j.1471-6402.1997.tb00104.x

Glick, P., \& Fiske, S. T. (1999). The Ambivalence Toward Men Inventory: Differentiating Hostile and Benevolent Beliefs About Men. Psychology of Women Quarterly, 23(3), 519-536. doi: 10.1111/j.1471-6402.1999.tb00379.x

Glick P, Lameiras M. Fiske ST. Eckes T. Masser B. Volpato C. et al., Bad but bold: Ambivalent

Sexist Attitudes toward Men Predict Gender Inequality in 16 Nations. Journal of Personality and Social Psychology. 2004; 86 (Suppl.5): 713-728.

McIntire, S. A., \& Miller, L. A. (2000). Foundation of Psychological Testing. Boston, MA: McGrawHill.

Sakallı Uğurlu, N. (2008). Turkish Adaptation of the Ambivalence toward Men Inventory. Türk Psikoloji Yazllar, 11(21), 01-11.

Tajfel, H. (1981). Social Identity and Intergroup Relations. London, UK: Cambridge University Press.

Tajfel, H., (1997) "Social Psychology of Intergroup Relations", Annual Review of Psychology, 33, s. 139. 